\title{
Genetic Counseling and Testing for Alzheimer's Disease and Frontotemporal Lobar Degeneration: An Italian Consensus Protocol
}

Martina Bocchetta ${ }^{\mathrm{a}, \mathrm{b}}$, Anna Mega ${ }^{\mathrm{a}}$, Livia Bernardic ${ }^{\mathrm{c}}$ Emilio Di Maria ${ }^{\mathrm{d}}$, Luisa Benussi ${ }^{\mathrm{e}}$, Giuliano Binetti ${ }^{\mathrm{f}}$, Barbara Borroni ${ }^{\mathrm{g}}$, Rosanna Colao ${ }^{\mathrm{c}}$, Giuseppe Di Fede ${ }^{\mathrm{h}}$, Silvia Fostinellie, Daniela Galimberti ${ }^{i}$, Massimo Gennarelli ${ }^{j}$, Roberta Ghidoni ${ }^{\mathrm{e}}$, Irene Piaceri ${ }^{\mathrm{k}}$, Michela Pievani ${ }^{\mathrm{a}}$, Corinna Porteri ${ }^{1}$, Veronica Redaellih ${ }^{\text {, Giacomina Rossi }}{ }^{\text {h }}$, Silvia Suardi ${ }^{\text {h }}$, Claudio Babiloni ${ }^{\mathrm{m}}$, Elio Scarpini ${ }^{\mathrm{i}}$, Fabrizio Tagliavini ${ }^{\mathrm{h}}$, Alessandro Padovani ${ }^{\mathrm{g}}$, Benedetta Nacmias ${ }^{\mathrm{k}}$, Sandro Sorbi ${ }^{\mathrm{k}}$, Giovanni B. Frisoni ${ }^{\mathrm{a}, \mathrm{n}}$, SINdem ${ }^{\ddagger}$, Amalia C. Bruni ${ }^{\mathrm{c}, *}$

${ }^{\ddagger}$ SINdem Collaborators:

Marco Bozzali ${ }^{o}$, Lucilla Parnetti ${ }^{\mathrm{p}}$, Carlo Ferrarese $^{\mathrm{q}}$, Stefano F. Cappa ${ }^{\mathrm{r}}$, Camillo Marra ${ }^{\mathrm{s}}$, Carlo Masullo $^{\mathrm{t}}$, Innocenzo Rainero ${ }^{\mathrm{u}}$, Vincenzo Silani ${ }^{\mathrm{v}}$, Giuseppe Sorrentino ${ }^{\mathrm{w}}$, Giuseppe Bruno ${ }^{\mathrm{x}}$, Annachiara Cagnin ${ }^{\mathrm{y}}$

${ }^{a}$ Laboratory of Alzheimer's Neuroimaging and Epidemiology, IRCCS Istituto Centro San Giovanni di Dio Fatebenefratelli, Brescia, Italy

${ }^{\mathrm{b}}$ Department of Molecular and Translational Medicine, University of Brescia, Brescia, Italy

${ }^{\mathrm{c}}$ Centro Regionale di Neurogenetica, ASP Catanzaro, Lamezia terme (CZ) Italy

${ }^{\mathrm{d}}$ Department of Health Sciences, University of Genova and Division of Medical Genetics, Galliera Hospital, Genova, Italy

e Molecular Markers Laboratory, IRCCS Istituto Centro San Giovanni di Dio Fatebenefratelli, Brescia, Italy

${ }^{\mathrm{f}}$ IRCCS Istituto Centro San Giovanni di Dio Fatebenefratelli, Brescia, Italy

${ }^{\mathrm{g}}$ University of Brescia and Centre for Ageing Brain and Neurodegenerative Disorders, Neurology Unit, Brescia, Brescia, Italy

${ }^{\mathrm{h}}$ IRCCS Fondazione Istituto Neurologico Carlo Besta, Milan, Italy

${ }^{\mathrm{i}}$ University of Milan, Fondazione Cà Granda, IRCCS Ospedale Maggiore Policlinico, Milan, Italy

${ }^{\mathrm{j}}$ Genetic Unit, IRCCS Istituto Centro San Giovanni di Dio Fatebenefratelli, Brescia, Italy

${ }^{\mathrm{k}}$ Department of Neuroscience, Psychology, Drug Research and Child Health, University of Florence, Florence, Italy

${ }^{1}$ Bioethics Unit, IRCCS Istituto Centro San Giovanni di Dio Fatebenefratelli, Brescia, Italy

${ }^{\mathrm{m}}$ Departiment of Physiology and Pharmacology, University of Rome "La Sapienza", Rome, Italy; IRCCS San Raffaele Pisana of Rome, Italy

\footnotetext{
*Correspondence to: Amalia Cecilia Bruni, MD; Centro Regionale di Neurogenetica, Viale Arturo Perugini, 88046 Lamezia Terme, Italy; Tel.: +390968 208080; Fax: +390968 208032; E-mail: bruni@arn.it.
} 
${ }^{\mathrm{n}}$ Memory Clinic and LANVIE - Laboratory of Neuroimaging of Aging, University Hospitals and University of Geneva, Geneva, Switzerland

${ }^{\circ}$ Neuroimaging Laboratory, IRCCS Santa Lucia Foundation, Rome, Italy

${ }^{\mathrm{P}}$ Section of Neurology, Department of Medicine, Centre for Memory Disturbances, University of Perugia, Perugia, Italy

${ }^{\mathrm{q}}$ School of Medicine and Surgery, Milan Center for Neuroscience (NeuroMI), University of Milano Bicocca, Italy; Neurology Unit, San Gerardo Hospital, Monza, Italy

${ }^{\mathrm{r}}$ NeTS Center-Istituto Universitario di Studi Superiori (IUSS), Pavia, Italy

${ }^{\mathrm{s}}$ Institute of Neurology and Center for Neuropsychological Research of the Policlinico Gemelli, Catholic University of Rome, Italy

${ }^{\mathrm{t}}$ Department of Neuroscience, Institutes of Neurology, Catholic University of the Sacred Heart, Rome, Italy

${ }^{\mathrm{u}}$ Neurology I - Headache Center, Department of Neuroscience "Rita Levi Montalcini, University of Torino, Torino, Italy

${ }^{\mathrm{v}}$ Department of Neurology-Stroke Unit and Laboratory of Neuroscience, IRCCS Istituto Auxologico Italiano,

“Dino Ferrari” Centre, Department of Pathophysiology and Transplantation, Universita' degli Studi di Milano, Milan, Italy

${ }^{\mathrm{w}}$ University of Naples Parthenope, Naples, Italy

"Memory Clinic, Department of Neurology and Psychiatry, University of Rome "Sapienza", Italy

${ }^{\mathrm{y}}$ Department of Neurosciences (DNS), University of Padova, Padua; IRCCS, San Camillo Hospital Foundation, Venice, Italy

Accepted 1 December 2015

Handling Associate Editor: Raquel Sánchez-Valle

\begin{abstract}
.
Background: Genetic testing of familial Alzheimer's disease (AD) and frontotemporal lobar degeneration (FTLD) is attracting interest thanks to innovative primary prevention clinical trials and increased request for information by at-risk individuals. However, ethical, social, and psychological implications are paramount and genetic testing must be supported by structured genetic counseling. In Italy, practice parameters and guidelines for genetic counseling in dementia are not available.

Objective: To develop a nationally harmonized protocol for genetic counseling and testing of familial AD and FTLD.

Method: Activities were carried out in the context of the Italian Dominantly Inherited Alzheimer's and Frontotemporal Network (IT-DIAfN) project, a national network of centers of excellence with expertise in managing patients with familial $\mathrm{AD}$ and FTLD. A survey of the literature on genetic counseling protocols and guidelines was conducted. Local protocols for genetic counseling were surveyed. Differences and commonalities among protocols were identified and discussed among project partners. Consensus was reached following implicit aggregation methods.

Results: Consensus was reached on a protocol for patients with clinically diagnosed familial AD or FTLD and a distinct protocol for their at-risk relatives. Genetic counseling should be provided by a multidisciplinary team including a geneticist, a neurologist/geriatrician, and a psychologist/psychiatrist, according to the following schedule: (i) initial consultation with tailored information on the genetics of the dementias; (ii) clinical, psychological, and cognitive assessment; if deemed appropriate (iii) genetic testing following a structured decision tree for gene mutation search; (iv) genetic testing result disclosure; (v) psychological support follow-up.

Conclusions: This genetic counseling protocol provides Italian centers with a line of shared practice for dealing with the requests for genetic testing for familial $\mathrm{AD}$ and FTLD from patients and at-risk relatives, who may also be eligible participants for novel prevention clinical trials.
\end{abstract}

Keywords: Alzheimer's disease, frontotemporal degeneration, genetic counseling, genetic testing

\section{INTRODUCTION}

Alzheimer's disease (AD) and frontotemporal lobar degeneration (FTLD) are two of the most common forms of dementia. Although the majority of cases are sporadic (i.e., without a family history), a markedly familial component has been reported in $60 \%$ of early onset ( $<65$ years) AD patients [1] and in $25-50 \%$ of FTLD patients [2, 3]. An autosomal dominant mode of inheritance is found in about 
$1-5 \%$ of $\mathrm{AD}$ and $10-50 \%$ of FTLD cases $[4,5]$ : specifically, pathogenic AD mutations were identified in the amyloid precursor protein $(A P P)$ [6] and the presenilin (PSEN1 and PSEN2) genes [7, 8], while the genes mainly involved in FTLD are the microtubule associated protein tau (MAPT) [9-11], the progranulin $(G R N)[12,13]$, and Chromosome 9 open reading frame $72(C 9$ orf 72$)[14,15]$. Since the majority of $G R N$ pathogenetic mutations cause protein haploinsufficiency, the dosage of circulating progranulin has been proposed as a useful tool for a quick and inexpensive large-scale screening of GRN mutations carriers [16-19].

Genetic testing for AD and FTLD is changing rapidly due to the increasing availability of new and faster technologies for DNA test, and it is attracting interest from patients and families thanks to innovative primary prevention clinical trials targeting genetic dementia and to the growing request for information by at-risk individuals. Two recent innovative clinical trials targeting genetic dementia are the Dominantly Inherited Alzheimer Network Trial for $\mathrm{AD}$ (DIAN-TU, http://www.clinicaltrials.gov/ show/NCT01760005) and the Presymptomatic Neurodegeneration Initiative for FTLD (PreNI, http://www.neurodegenerationresearch.eu/initiatives/ jpnd-alignment-actions/longitudinal-cohorts/call-for -working-groups/call-results/). Genetic mutation carriers, both symptomatic and asymptomatic, could therefore be eligible participants for these novel clinical trials.

Genetic testing in symptomatic patients is used to confirm the clinical diagnosis (diagnostic DNA test); genetic testing in cognitively unimpaired relatives of patients with a mutation identifies those who will develop the disease in the future (predictive DNA test) [20-23]. In at-risk asymptomatic relatives, predictive genetic testing offers the possibility of assessing their personal risk, thus allowing them to organize their lives and make informed career or reproductive choices and decisions [23]. Undergoing predictive tests may help at-risk individuals to cope emotionally with their genetic risk by reducing uncertainty about their status and focusing on planning for the future [24], as suggested by a seminal study in Huntington's disease [25]. As compared to Americans, Italian atrisk relatives expressed higher intentions to undergo genetic testing [20].

However, together with these potential advantages, genetic tests have important ethical, social, legal, and psychological implications for the patients and the whole family. In fact, the identification of a genetic mutation in a patient implicitly defines the risk for the other family members, with possible implication for their health and their future. On the other hand, information on genetic status cannot be sensibly used for therapeutic purposes, as no approved diseasemodifying treatment is available to date. In healthy at-risk individuals, there are concerns that a positive genetic testing may trigger a negative psychological response, such as severe depression, anxiety, helplessness, or even suicidal ideation [26]. From a social/legal perspective, there may be issues of potential genetic discrimination, difficulties in finding a job or service assistance (including insurance implications), and in creating relationships [21].

Current guidelines for $\mathrm{AD}$ and other inherited dementia recommend that genetic testing should be offered within a proper genetic counseling procedure [21]. For asymptomatic at-risk individuals, the protocol established for Huntington's disease, recently revised [27], is recommended.

With the advent of the prevention clinical trials in dementia, such as DIAN-TU for AD in presymptomatic mutation carriers, disclosure of genetic status is a pre-condition to participate in a trial in Italy. Such disclosure cannot be made without effective preand post-genetic testing support [28].

To date, in Italy no practice standards and consensus-based guidelines are available for genetic counseling of familial AD or FTLD. The IT-DIAfN project, a network of Italian centers of excellence with recognized experience in managing patients with familial AD and FTLD, aimed at developing a harmonized and structured protocol for genetic testing and counseling for those families, both for symptomatic patients and at-risk relatives. As inherited AD and FTLD are genetically heterogeneous and symptoms often overlap, we also generated a decision tree to assist clinicians/researchers in mutations search.

\section{METHODS}

This study was conducted as part of the "Italian Dominantly Inherited Alzheimer's and Frontotemporal Network (IT-DIAfN)", a national project funded by the Italian Ministry of Health (RF-2010-2319722, Bando Ricerca Finalizzata 2010). It gathers six centers of excellence in the study of genetic AD and FTLD: IRCCS Istituto Centro San Giovanni di Dio Fatebenefratelli of Brescia, IRCCS Fondazione Istituto Neurologico Carlo Besta of Milan, University of Florence, Centro Regionale di Neurogenetica of Lamezia Terme, University of Brescia, 
and Fondazione IRCCS Cà Granda Ospedale Maggiore Policlinico of Milan.

A working group was composed by geneticists, psychologists, neurologists, and bioethicists, with at least one representative from each center, with the collaboration of the Department of Health Sciences, University of Genova and Division of Medical Genetics, Galliera Hospital, Genova.

As a first step, the group conducted a survey of genetic counseling protocols approved by the local ethics committees and in use at each center. In particular, the group collected information regarding the professionals involved in the genetic counseling team, tests used for the assessment, phases, procedures, timelines, informed consent forms, access criteria, and specific requests from the local ethics committees. Moreover, other specific issues were addressed, such as the informed consent/refusal for storage of the biological samples in a biobank for possible future research studies. Literature search and experience from centers were combined to develop a decision tree to assist in the search of the mutation, to be more accurate, and to reduce time and cost.

A literature search was conducted to analyze guidelines or recommendations available for other genetic diseases, such as Huntington's disease [27, 29,30], or in use in other countries. Italian regulations for data protection were considered (The Italian Data Protection Authority, General Authorisation No. 8/2014 for the Processing of Genetic Data, doc. web No. 3632835).

In February-March 2013 the working group participated in the first meetings (one in-person and one $a$ remoto, via teleconferences) aimed at identifying and discussing the surveyed differences and commonalities among protocols. The first draft was discussed during an in-person meeting in July 2013 and circulated to the working group in the ensuing months. All comments and feedbacks were periodically summarized and collated by the Project Coordinator, who was in charge of moderating the discussion via electronic communication and of reconciling the different viewpoints to reach a consensus. The final consensus was reached in October 2014 following implicit aggregation methods [31]: the group experts in each field guided the decision-making process and the final consensus was defined by majority position. Further comments from SINdem (Italian Society for the study of Dementias) were also taken into account.

The harmonized protocol for genetic counseling was approved in February 2015 by the Ethics Committee of the Coordinating Centre of the IT-DIAfN project (IRCCS Istituto Centro San Giovanni di Dio Fatebenefratelli of Brescia).

\section{RESULTS}

\section{Survey for Local Protocols}

The results of the survey are reported in Table 1. In all centers, a multidisciplinary team, including a geneticist, a neurologist, and a psychologist or a psychiatrist, provided genetic counseling. The schedule of the consultation and the procedures varied among centers. Three centers divided the procedure into three consultations: the first was an informational meeting, where the family history was collected and the subjects underwent a neurological and a psychological examination; the second was the blood sample collection, while the third was the disclosure of the genetic test results. The other three centers divided the pre-test phase into two visits: one informational and one for the assessment of the patient. The timetable for the visits and for the supportive follow-up varied from center to center. Moreover, some centers considered the follow-up as non-mandatory or they offered it only in case of positivity of the test. Different tests were used to assess different domains locally (Table 1). Only two centers had a specific protocol for symptomatic subjects (diagnostic test), while all centers had a protocol for at-risk relatives.

\section{Harmonized Protocol for Genetic Counseling}

\section{Target population}

Genetic counseling can be requested (and eventually stopped or suspended at any stage) by (i) symptomatic patients with a positive family history suggestive of an autosomal dominant genetic cause for AD and FTLD and (ii) relatives of patients with proven genetic AD or FTLD. Each subject has to be $\geq 18$ years old. A positive family history is defined within the group based on the presence of one of the following criteria: i) at least three affected first-degree relatives in two generations, irrespectively of the age at onset (AAO); ii) at least two affected first-degree relatives in two generations, with at least one with onset at $\leq 65$ years; or iii) one affected family member with onset at $\leq 60$ years or with a suggestive clinical phenotype (e.g. dementia with atypical presentation [32], recurring presence in other relatives, peculiar geographic origin).

Cognitively unimpaired at-risk relatives enter the counseling and are eligible to undergo the genetic 


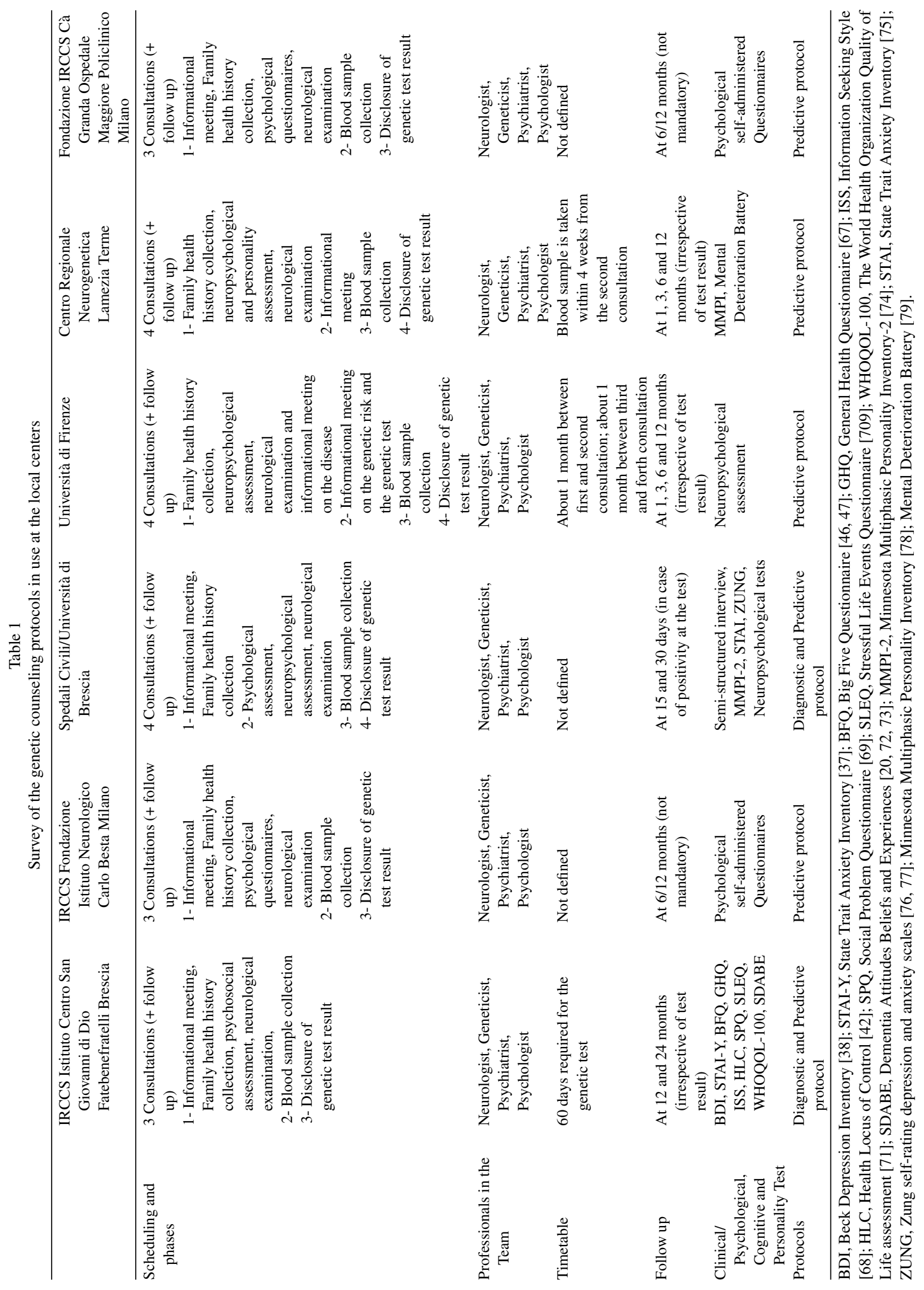


testing only after the proven presence of the mutation in a first-degree symptomatic relative.

Two specific genetic counseling protocols were defined: one for symptomatic patients (Section Protocol for symptomatic subjects) and one for at-risk relatives, with a more relaxed and prolonged schedule (Section Protocol for at-risk subjects).

\section{Genetic counseling team}

Genetic counseling is provided by a multidisciplinary team of health professionals who work together to provide an individual or a family with current information and supportive counseling about genetic testing. Genetic counseling is structured and guided by a geneticist and by a specialized medical doctor with specific competences in neurodegenerative diseases. The geneticist, who had education in genetic counseling, is a specialist in medical genetics with expertise in neurodegenerative diseases. The specialized medical doctor (neurologist, geriatrician, and/or psychiatrist) is the clinical contact person for the patient: this role can be also played by the geneticist, but only if he/she is a medical doctor with a consolidated clinical background for the aforementioned diseases. Beside the geneticist and the specialized medical doctor, the multidisciplinary team is composed by other professionals (i.e., a psychologist and/or a psychiatrist), who have expertise in counseling, and have skills at providing ongoing support to individuals with possible socio-psychological consequences associated with the risk of being a mutation carrier.

\section{Evaluation tests}

A common battery of clinical, psychological, and cognitive tests was defined for symptomatic patients and their at-risk relatives. Specifically, the battery includes the Mini-Mental State Examination (MMSE) [33] and the Clinical Dementia Rating Scale (CDR) [34], the Questionnaire on the Health Status12 (SF-12) [35] and the World Health Organization Quality of Life (WHOQOL) [36], for the assessment of quality of life and health status; the State Trait Anxiety Inventory (STAI-Y) [37], the Beck Depression Inventory (BDI) [38], and the Hamilton Rating Scale for Depression (HRSD) [39], for anxiety and depression measurement; the Brief COPE (BC) [40], the Resilience Scale for Adult (RSA) [41], and the Health Locus of Control (HLC) [42, 43], for the evaluation of the coping style and the locus of controls. Moreover, a depth evaluation of the risk of suicide is recommended, if the subject showed suicidal thoughts or attitudes in the past or at present (item 9 of BDI and/or item 3 of HRSD). One suggested scale is the Beck Hopelessness Scale [44, 45]. In addition to these tests, the at-risk relatives are also assessed with the Big Five Questionnaire (BFQ) for personality assessment $[46,47]$.

The subject is assessed at a pre-test phase, to investigate his/her ability to cope with the test result. Except for the MMSE, the CDR, and the BFQ, the assessment with the other tests is repeated post-test at different time-points, to monitor the psychological status of the subject, as specified later in the text and in Fig. 1A-B.

Based on the profile of the subject, the multidisciplinary team can suggest postponement of the genetic test. The team continues to follow and support the individual as long as it is deemed necessary by the team or requested by the subject.

\section{Protocol for symptomatic subjects}

The genetic testing for symptomatic subjects has a diagnostic purpose, i.e., to identify the genetic cause of the disease and confirm the diagnosis of $\mathrm{AD}$ or FTLD. The procedures are illustrated in Fig. 1A and include: at least one pre-test consultation, one meeting for blood withdrawal for the genetic testing, a post-test consultation, where the genetic status is disclosed (for those who wish to know) and then three follow-ups. The number of the consultations can be increased and the timespan relaxed, if required by the patients of if considered appropriate by the team. Genetic counseling for symptomatic patients should be performed in the presence of the caregiver according to patient's will, and the individual's legal guardian if appointed for the individual patient, to help the patient in the decision-making process, specifically to help in understanding and appreciating the purpose and possible results of the genetic test and in expressing a choice [21, 48].

First consultation: pre-test. During the first informational visit, the whole multidisciplinary team provides general information regarding the familial forms of dementia and details about genetic counseling (i.e., timespan, team roles, aims, and procedures), the reliability of the test, and the interpretation of the results. The team should explain medical and genetic terms and avoid technical jargon. The implications of both positive and negative test result are discussed, as well as if and how these results will be communicated to other family members. Patients and their families should understand that multiple possible results 


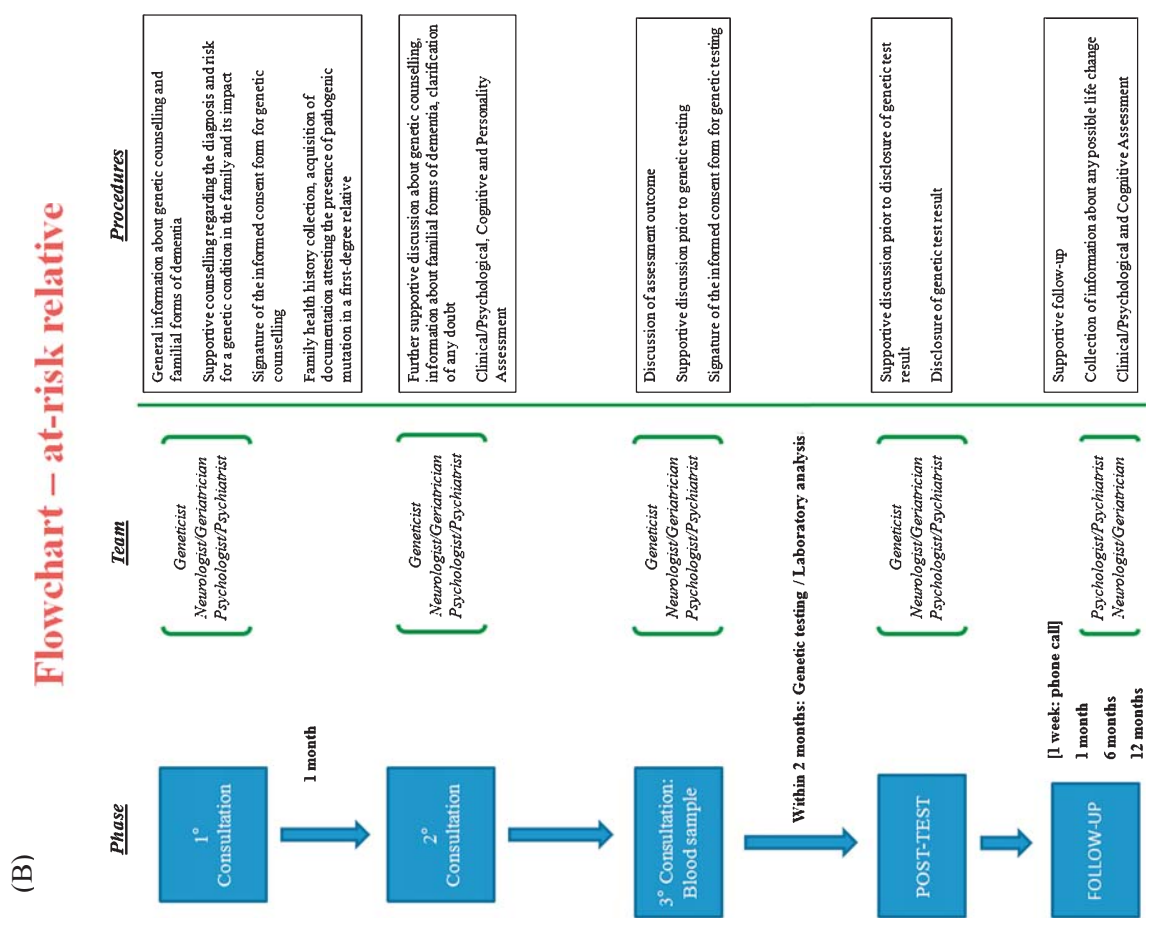

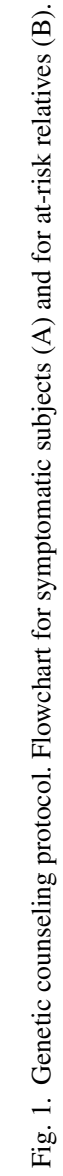

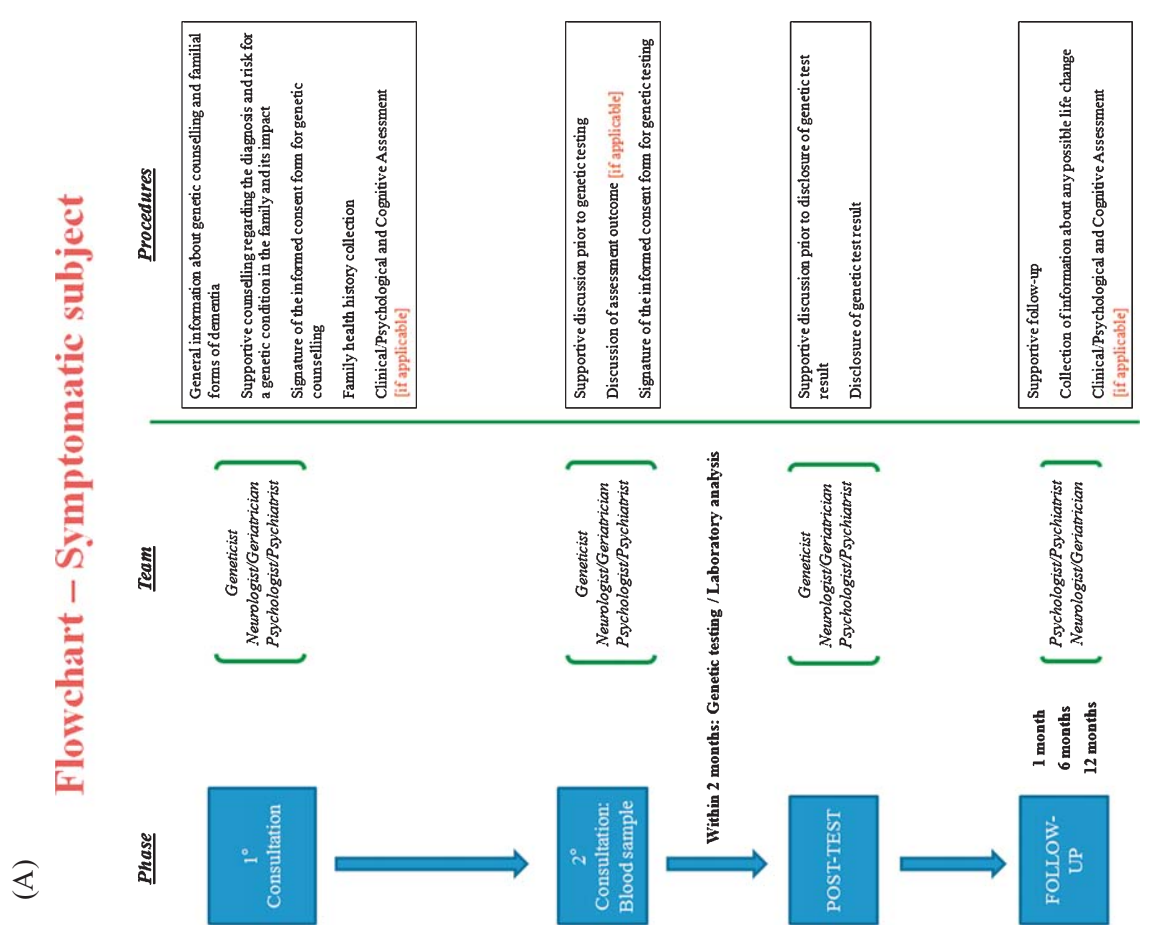


may be revealed: a causative mutation in one of the genes, no mutation in any of the genes, a variant of unknown significance, or even mutations or variants in more than one genes. Supportive information is given regarding the diagnosis and risk for the genetic disease in the family and its clinical, psychological, sociological, and ethical implications, together with the impact on the family members. The specific implications, prospective benefits, and risks of undergoing genetic testing are discussed. The aim is to provide as much clear information as possible, and discuss any question or doubt, to allow subjects to take an autonomous and informed decision whether they are willing to undergo genetic counseling and testing and to know their genetic status. The team avoids influencing the decision of the individual and the family, and aims at facilitating their autonomous decision-making.

If agreed, the subject, and/or his/her legal guardian on his/her behalf if appropriated, signs the informed consent form for genetic counseling. The caregiver, if present according to patient's wishes, can also sign the informed consent to express agreement [48]. The family health history is collected to construct the family pedigree and, where possible, a complete family history should be collected using a structured questionnaire. Personal clinical phenotype and family history will be used to guide the algorithm for mutation search (see "Flowchart for genetic testing") and to evaluate whether the genetic test is appropriate (as a guide: $[49,50])$.

Finally, if not too severely impaired, the subject is assessed using the test described in "Evaluation tests".

After the consultation, the team provides the patient with a written summary or brochure with all the general information discussed in person, to allow their elaboration and comprehension. In case of doubts, a second informational visit can be scheduled.

Second consultation: blood sample collection. At the beginning of the second consultation, the whole team evaluates whether all the information provided during the first visit was fully understood, and it clarifies any remaining doubts or new questions that may arise. The results of the assessment (if done) are discussed. If the patient wishes to proceed with the test, the subject, and/or his/her legal guardian on his/her behalf if appropriated, signs the informed consent for genetic testing and blood sample is collected. The caregiver, if present according to patient's wishes, can also sign the informed consent to express agreement. At this stage, the patient can decide whether his/her sample can be stored in a biobank for possible future research studies on genetic forms of dementia or destroyed after the completion of the analyses.

The team informs the patient about the timespan for the completion of molecular genetic analysis (around two months).

Third consultation: post-test. Within two months from the blood sample collection, the results are made available. If the patient still wishes to know, the genetic test results are disclosed and discussed with the patient, and a written report is given. The whole team should assess the individual's understanding of his/her situation and adapt the language to the patient in order to clearly explain the meaning and the implications of a positive, negative, or unclear test result.

The team should support and assist the patient and the family in expressing their emotional reactions to their genetic status. Before leaving the visit, the presence of psychological distress should be informally assessed.

Follow-up. After the disclosure of the results, the team offers ongoing support and information. Three different time points for the follow-up were defined: after 1, 6, and 12 months from the disclosure. The team collects information about any possible change that may have occurred in the family and in his/her everyday life. The patient is qualitatively assessed about his/her psychological conditions, and the tests described in "Evaluation tests" are administered, whenever possible.

\section{Protocol for at-risk subjects}

The predictive test in genetic counseling aims at confirming whether the genetic mutation identified in the family has been inherited by the at-risk relative, at a stage where the individual does not present any symptom. This protocol leads to many more ethical and psychosocial issues than the diagnostic test in symptomatic subjects, because the potential identification of being a carrier of an autosomal dominant mutation almost certainly predicts the future development of the disease in an individual that is currently healthy. Undergoing a predictive test is a highly personal decision that demands extensive counseling.

The procedures are illustrated in Fig. 1B and detailed below. The schedule mainly differs from the diagnostic test in prescribing at least two pre-test consultations before the genetic testing, and in having a 
phone call one week after the disclosure of the genetic status.

First consultation: pre-test. As for the symptomatic patients, the first consultation is an informational and supporting visit, when the whole team covers specific issues of the familial forms of dementia, genetic counseling and testing, and the implications of the results (for further details see "First consultation: pre-test" of "Protocol for symptomatic subjects"). The presence of a support person is encouraged.

If agreed, the subject signs the informed consent form for genetic counseling. Then, there is an evaluation of the personal and familial medical history.

After the consultation, the team provides the subject with a written summary or brochure with all the general information discussed in person, to allow their elaboration and comprehension.

Second consultation: pre-test. After one month from the first visit, the second one is scheduled, to further discuss the motivation for the predictive test and clarify any doubts which may have arisen.

The subject is assessed using the tests described in "Evaluation tests".
Third consultation: blood sample collection. The procedures are the same as for the symptomatic protocol (see "Follow-up" of "Protocol for symptomatic subjects").

Fourth consultation: post-test. The procedures are the same as for the symptomatic protocol (see "Third consultation: post-test").

Follow-up. One week after the disclosure of the results, the team (specifically the psychologist and/or psychiatrist), contacts the subject by phone and offers ongoing support and information. The other followup visits are the same as for the symptomatic protocol (see "Follow-up" of "Protocol for symptomatic subjects").

\section{Flowchart for genetic testing}

A decision tree was developed to assist in the search of the mutation in symptomatic patients (Fig. 2).

If the patient has recently undergone a lumbar puncture and $\mathrm{A} \beta$ and tau levels in the cerebrospinal fluid (CSF) have been analyzed, this measure guides the genetic screening. If the CSF tau and $A \beta_{42}$ levels are abnormal (i.e., tau $/ A \beta_{42}>0.52$ ) [51], genetic

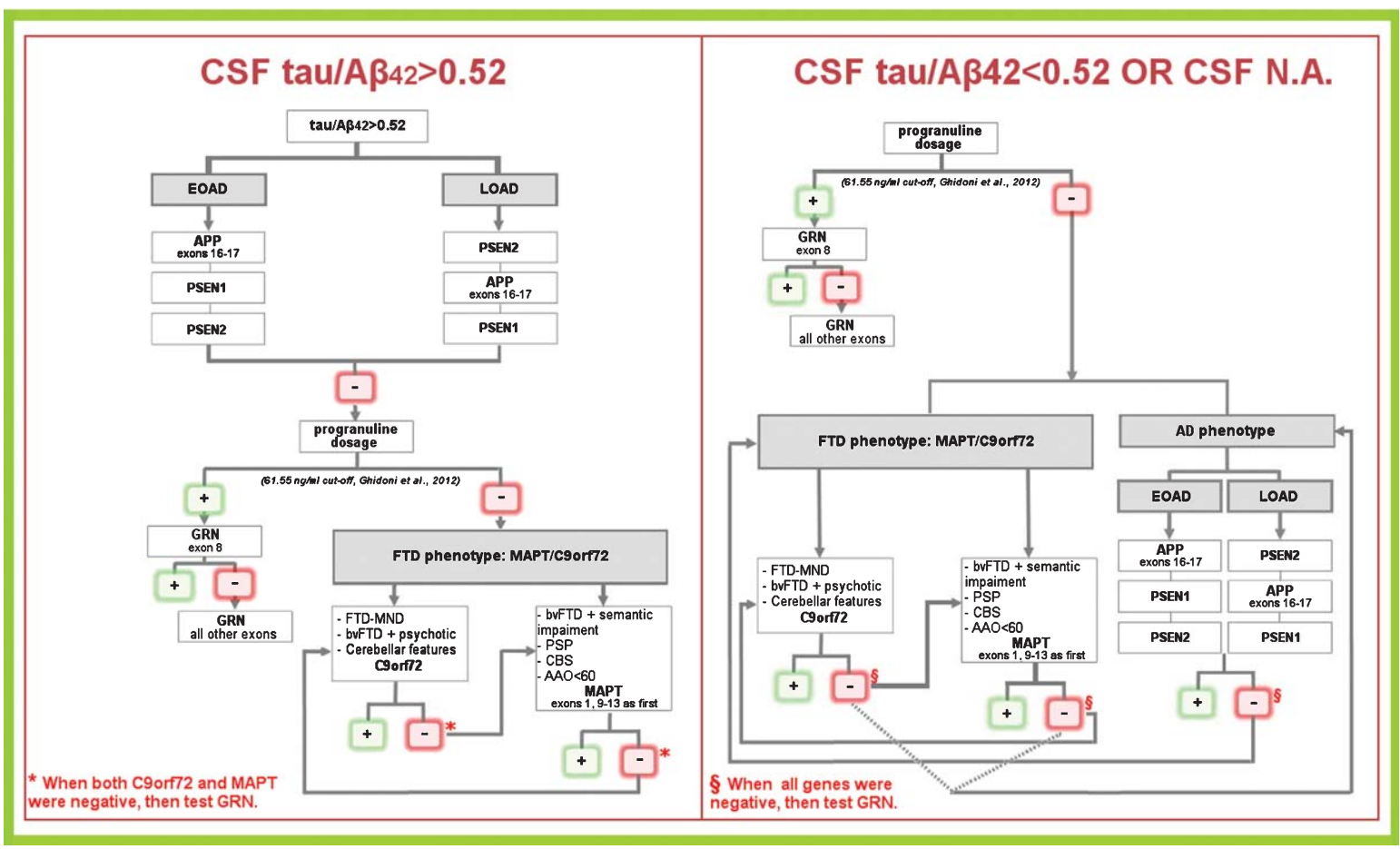

Fig. 2. Genetic testing flowchart. Step-by-step algorithm to assist in the search of genetic mutations, for cases with abnormal A $\beta$ and tau levels in the cerebrospinal fluid (CSF) (left panel) and with normal CSF values or data not available (right panel). 
mutations linked to AD are searched as first. To determine which gene should be sequenced first (i.e., $A P P$, PSEN1, or PSEN2), the patient's AAO is considered: if the patient has an early AAO ( $\leq 65$ years), $A P P$ gene (exons 16-17) is sequenced; if negative: all PSEN1 exons and flanking regions; if negative: all PSEN2 exons and flanking regions. Instead, if the patient has a late AAO, PSEN2 gene is the first choice for sequencing, and then APP and PSEN1. If all AD genes are mutation-negative, but there is a strong evidence for an autosomal dominant pattern, then genes linked to FTLD are screened. Plasma progranulin dosage for GRN null mutation screening has the priority: if the level is $<61.55 \mathrm{ng} / \mathrm{ml}$ [19], the presence of the common Italian p.L271fs (exon8:c.811_814del, ref sequence NM_002087) mutation is assessed [52]; if no mutation is found, all other exons are sequenced. Conversely, if the progranulin level is not suggestive for the presence of null mutations (i.e., $>61.55 \mathrm{ng} / \mathrm{ml}$ ), the clinical phenotype is taken into account. C9orf72 genetic screening should have the priority in patients with FTLD and motor neuron disease (FTD-MND), behavioral variant frontotemporal dementia (bvFTD) with psychosis, or FTLD with cerebellar features, while MAPT gene (exons 1, 9-13, as first) should be the first choice in patients with bvFTD and semantic dementia, progressive supranuclear palsy (PSP), corticobasal syndrome (CBS), or an early AAO $(<60$ years). When both C9orf72 and MAPT resulted negative, then $G R N$ should be tested, given possible false negative in progranulin plasma screening.

When CSF tau and A $\beta$ levels are normal or not available, the algorithm is based on the progranulin dosage, as described previously. When the patient's level of progranulin is normal, the clinical phenotype is taken into account for guiding the analysis. If the clinical phenotype is FTD-like, then the priority between $C 9$ orf72 and MAPT is defined as previously described. If the clinical phenotype is consistent with $\mathrm{AD}$, then, according to the AAO, APP, PSEN1, and PSEN2 are screened as described previously. When no mutation is found, the other branch in the diagram is followed (Fig. 2).

Lastly, if the DNA analysis is done in an at-risk subject, only the mutation found in the symptomatic relative is searched for.

\section{DISCUSSION}

Genetic testing has ethical, social, legal, and psychological implications for patients and their family: when handled by an experienced and qualified multi- disciplinary team following structured criteria, these issues can be faced serenely and confidently by families. Here, we present a standard and structured protocol for genetic testing and counseling for symptomatic and at-risk individuals belonging to families with suspected forms of autosomal dominant $\mathrm{AD}$ or FTLD. This protocol is not designed for genetic counseling of people who carry susceptibility genetic risk for $\mathrm{AD}$, such as the apolipoprotein $\mathrm{E} \varepsilon 4$ allele, as this is only a risk factor for dementia and no definitive prediction can be made about dementia in these subjects. Moreover, based on the current knowledge, we would not recommend genetic counseling to all sporadic FTD cases as the likelihood of finding a mutation in cases with a negative family history is presumably low [49] and would thus unnecessarily increase burden to patients and their families. The ITDIAfN protocol provides guidance on the schedule, the procedures, the tests, and the professional figures involved in genetic counseling, with the aim to support and take responsible care of these families. The tests for clinical, cognitive, and personality assessment were accurately chosen to obtain a concise but accurate profile of the individual, helping in personalizing and adapting the support within the counseling to his/her possible reactions.

We have taken into account the guidelines for the genetic testing of Huntington's disease [27, 29, 30], which is considered the gold standard for genetic testing for adult onset diseases. As recommend by these guidelines, we used a multidisciplinary approach to facilitate the subject's autonomous decision making: the geneticist as the expert in genetic counseling for AD and FTLD, the specialized medical doctor as the clinical contact person of the patients; and the psychologist/psychiatrist as the contact person for counseling, psychological appraisal, and support. The schedule and timespan of the visits are similar to those defined for Huntington's disease: several sessions and phases (pre-, post-testing, and follow-ups) are crucial to allow free choice, without rushing into genetic testing before all the necessary explanations and information are given. Other recommendations prescribed in the Huntington's disease guidelines were adopted here: i) disclosure of the genetic status is provided both orally and through a written report; ii) availability of the test only to individuals who have come of age; iii) possibility of storing the biological samples in a biobank for research studies after signing the informed consent.

As described in other existent counseling protocols for AD and FTLD [21, 22], we recommended 
that i) the legal guardian of the symptomatic patient is present during the counseling to help her/him in understanding its purpose and possible results of the genetic test and in expressing a choice, and that ii) a symptomatic family member should be tested before an at-risk individual.

The guidelines for genetic counseling for $\mathrm{AD}$ defined by the American College of Medical Genetics and the National Society of Genetic Counselors [21] specified that genetic counseling could be done in-person or through videoconferences. The Huntington's disease guidelines clearly stated that the results of the test should be revealed in-person, and not by phone or mail [27, 30], while psychosocial support should be available close to the person's community, by phone or telemedicine where necessary. A few pilot projects demonstrated that telemedicine can be used to offer medical genetics service on a remote basis [53]. Preliminary evidence suggests that genetic counseling can be effectively delivered in underserved areas, also in late-onset genetic disorders such as familial cancer [54]. The advent of telegenetics could allow the implementation of this genetic counseling protocol in clinical research centers without lowering the clinical standard; it may also facilitate the enrolment in clinical trials of individuals who could not access to tertiary care genetics centers. Nevertheless, it is recommended that the psychologist/psychiatrist should be always present in person during the visits.

We developed two specific paths, one for symptomatic patients and one for asymptomatic at-risk subjects, being aware of the difference of the two scenarios. In fact, in symptomatic subjects, genetic testing is aimed at confirming the clinical diagnosis and the genetic cause of the disease. A positive result can provoke hopelessness and sense of guilty for the possibility of transmission of the mutation to the offspring. In the case of asymptomatic subjects, psychological, social, and ethical issues are even more critical, especially in the absence of prevention or treatment options: a correct and careful counseling will offer them the option of knowing their condition, cope positively with their future and eventually they might be offered the possibility to enter a novel prevention clinical trial. It must be underlined that a negative result has different meanings according to the two different scenarios: in a symptomatic subject, this could not exclude definitely that the disease has a genetic cause (thus it is sporadic), because an unknown/new mutation could be present but not yet been discovered; in an at-risk relative, a negative result confirms almost with absolute certainty that he/she has not inherited the causative mutation found in the affected relative and thus he/she has the same risk of the general population to develop the disease in the future.

Considering the results reported in Binetti et al. [20], Italian families with familial dementia showed poor knowledge of the disease and poor awareness of personal risk of developing dementia during lifetime. This means that the first consultation should address these aspects in details, guiding families to a free and informed choice.

We developed a step-by-step algorithm for guiding genetic screening on the basis of biomarker results and clinical data, to reduce time and cost of the laboratory analysis. Specifically, the decision tree was defined according to (i) the observed frequency of genes in specific clinical phenotypes in the literature $[49,55-58]$, and specifically in Italian clinical series [52, 59-65], (ii) the direct experience of the Italian centers, and (iii) practical considerations, e.g., the high speed and low cost of a given screening procedure (i.e., plasma progranulin dosage). In the future, other biomarkers can be taken into account and implemented within the flowchart, such as the amyloid PET.

The research protocol reported herein reflects the current practice of Italian centers taking part to the IT-DIAfN initiative. Should important innovations be introduced in the clinical practice as well as in laboratory analyses, the protocol will be amended. Following the wide availability of next generation sequencing (NGS) panels for the molecular genetics analysis, the decision tree is subject to changes accordingly. NGS is not currently applied in all centers participating into the IT-DIAfN framework, but appears as the upcoming technology for the mutation analysis in heterogeneous genetic disorders such as AD and FTLD. To date, the NGS approach provides the simultaneous analysis of a panel of 17 genes (PRNP, PSEN1, PSEN2, APP, GRN, MAPT, TREM2, CHMP2B, CSF1R, FUS, ITM2B, NOTCH3, SERPINI1, TARDBP, TYROBP, VCP, SQSTM1). Other experimental panels of additional genes and SNP polymorphisms are currently under development within the IT-DIAfN group. The mutation search should be completed with two PCR analyses of the $C 9$ orf72 hexanucleotide repeat expansion and the octapeptide repeat region of $P R N P$ [66].

This protocol, developed by experts in the field, provides Italian centers with a line of shared practice for offering genetic counseling to eligible individu- 
als who may benefit from genetic testing for familial $\mathrm{AD}$ and FTLD, and recruit them through a procedure which is compliant with International recommendations and good practices.

Future steps will be the validation of the harmonized protocol of genetic counseling. This will be performed in two steps: i) after approval by local ethics committees, the protocol will be implemented in all centers participating into the IT-DIAfN project; ii) data from each center will be collected and the results from the pilot stage will be critically reviewed by the working group who developed the protocol. The genetic counseling protocol will also be disseminated through medical societies and proposals for amendments will be acknowledged.

We are aware that the entire procedure, including counseling, repeated assessments, and testing, is highly demanding, especially in terms of human resources. The procedure is expected to be accomplished within a research environment by a multidisciplinary team in centers with specific expertiseas such it was not designed to be applied in routine clinical practice in its current version. In the light of the suggestion raised during the validation phase, an optimized protocol could be eventually transferred to clinics, provided that evidence of clinical utility has been produced and a health technology assessment has supported its implementation in clinical practice.

\section{ACKNOWLEDGMENTS}

This study was funded through "Italian Dominantly Inherited Alzheimer's and Frontotemporal Network (IT-DIAfN)", a project funded by the Italian Ministry of Health (RF-2010-2319722, Bando Ricerca Finalizzata 2010) and coordinated by Giovanni B. Frisoni at the IRCCS Istituto Centro San Giovanni di Dio Fatebenefratelli, Brescia, Italy.

Authors' disclosures available online (http://j-alz. com/manuscript-disclosures/15-0849r1).

\section{REFERENCES}

[1] Bird TD (2008) Genetic aspects of Alzheimer disease. Genet Med 10, 231-239.

[2] Rohrer JD, Guerreiro R, Vandrovcova J, Uphill J, Reiman D, Beck J, Isaacs AM, Authier A, Ferrari R, Fox NC, Mackenzie IR, Warren JD, de Silva R, Holton J, Revesz T, Hardy J, Mead S, Rossor MN (2009) The heritability and genetics of frontotemporal lobar degeneration. Neurology 73, 14511456.

[3] Seelaar H, Rohrer JD, Pijnenburg YA, Fox NC, van Swieten JC (2011) Clinical, genetic and pathological heterogeneity of frontotemporal dementia: A review. J Neurol Neurosurg Psychiatry 82, 476-486.

[4] Bekris LM, Yu CE, Bird TD, Tsuang DW (2010) Genetics of Alzheimer disease. J Geriatr Psychiatry Neurol 23, 213227.

[5] Warren JD, Rohrer JD, Rossor MN (2013) Clinical review. Frontotemporal dementia. Br Med J 347, f4827.

[6] Goate A, Chartier-Harlin MC, Mullan M, Brown J, Crawford F, Fidani L, Giuffra L, Haynes A, Irving N, James L, Mant R, Newton P, Rooke K, Roques P, Talbot C, PericakVance M, Roses A, Williamson R, Rossor M, Owen M, Hardy J (1991) Segregation of a missense mutation in the amyloid precursor protein gene with familial Alzheimer's disease. Nature 349, 704-706.

[7] Sherrington R, Rogaev EI, Liang Y, Rogaeva EA, Levesque G, Ikeda M, Chi H, Lin C, Li G, Holman K, Tsuda T, Mar L, Foncin JF, Bruni AC, Montesi MP, Sorbi S, Rainero I, Pinessi L, Nee L, Chumakov I, Pollen D, Brookes A, Sanseau P, Polinsky RJ, Wasco W, Da Silva HA, Haines JL, Perkicak-Vance MA, Tanzi RE, Roses AD, Fraser PE, Rommens JM, St George-Hyslop PH (1995) Cloning of a gene bearing missense mutations in early-onset familial Alzheimer's disease. Nature 375, 754-760.

[8] Sherrington R, Froelich S, Sorbi S, Campion D, Chi H, Rogaeva EA, Levesque G, Rogaev EI, Lin C, Liang Y, Ikeda M, Mar L, Brice A, Agid Y, Percy ME, Clerget-Darpoux F, Piacentini S, Marcon G, Nacmias B, Amaducci L, Frebourg T, Lannfelt L, Rommens JM, St George-Hyslop PH (1996) Alzheimer's disease associated with mutations in presenilin 2 is rare and variably penetrant. Hum Mol Genet 5, 985-988.

[9] Hutton M, Lendon CL, Rizzu P, Baker M, Froelich S, Houlden H, Pickering-Brown S, Chakraverty S, Isaacs A, Grover A, Hackett J, Adamson J, Lincoln S, Dickson D, Davies P, Petersen RC, Stevens M, de Graaff E, Wauters E, van Baren J, Hillebrand M, Joosse M, Kwon JM, Nowotny P, Che LK, Norton J, Morris JC, Reed LA, Trojanowski J, Basun H, Lannfelt L, Neystat M, Fahn S, Dark F, Tannenberg T, Dodd PR, Hayward N, Kwok JB, Schofield PR, Andreadis A, Snowden J, Craufurd D, Neary D, Owen F, Oostra BA, Hardy J, Goate A, van Swieten J, Mann D, Lynch T, Heutink $\mathrm{P}$ (1998) Association of missense and 5'-splice-site mutations in tau with the inherited dementia FTDP-17. Nature 393, 702-705.

[10] Poorkaj P, Bird TD, Wijsman E, Nemens E, Garruto RM, Anderson L, Andreadis A, Wiederholt WC, Raskind M, Schellenberg GD (1998) Tau is a candidate gene for chromosome 17 frontotemporal dementia. Ann Neurol 43, 815-825.

[11] Spillantini MG, Murrell JR, Goedert M, Farlow MR, Klug A, Ghetti B (1998) Mutation in the tau gene in familial multiple system tauopathy with presenile dementia. Proc Natl Acad Sci U S A 95, 7737-7741.

[12] Baker M, Mackenzie IR, Pickering-Brown SM, Gass J, Rademakers R, Lindholm C, Snowden J, Adamson J, Sadovnick AD, Rollinson S, Cannon A, Dwosh E, Neary D, Melquist S, Richardson A, Dickson D, Berger Z, Eriksen J, Robinson T, Zehr C, Dickey CA, Crook R, McGowan E, Mann D, Boeve B, Feldman H, Hutton M (2006) Mutations in progranulin cause tau-negative frontotemporal dementia linked to chromosome 17. Nature 442, 916-919.

[13] Cruts M, Gijselinck I, van der Zee J, Engelborghs S, Wils H, Pirici D, Rademakers R, Vandenberghe R, Dermaut B, Martin JJ, van Duijn C, Peeters K, Sciot R, Santens P, De Pooter T, Mattheijssens M, Van den Broeck M, Cuijt I, Vennekens K, De Deyn PP, Kumar-Singh S, Van Broeckhoven C (2006) Null mutations in progranulin cause ubiquitin-positive 
frontotemporal dementia linked to chromosome $17 \mathrm{q} 21$. Nature 442, 920-924.

[14] DeJesus-Hernandez M, Mackenzie IR, Boeve BF, Boxer AL, Baker M, Rutherford NJ, Nicholson AM, Finch NA, Flynn H, Adamson J, Kouri N, Wojtas A, Sengdy P, Hsiung GY, Karydas A, Seeley WW, Josephs KA, Coppola G, Geschwind DH, Wszolek ZK, Feldman H, Knopman DS, Petersen RC, Miller BL, Dickson DW, Boylan KB, GraffRadford NR, Rademakers R (2011) Expanded GGGGCC hexanucleotide repeat in noncoding region of C9ORF72 causes chromosome 9p-linked FTD and ALS. Neuron 72, 245-256

[15] Renton AE, Majounie E, Waite A, Simón-Sánchez J, Rollinson S, Gibbs JR, Schymick JC, Laaksovirta H, van Swieten JC, Myllykangas L, Kalimo H, Paetau A, Abramzon Y, Remes AM, Kaganovich A, Scholz SW, Duckworth J, Ding J, Harmer DW, Hernandez DG, Johnson JO, Mok K, Ryten M, Trabzuni D, Guerreiro RJ, Orrell RW, Neal J, Murray A, Pearson J, Jansen IE, Sondervan D, Seelaar H, Blake D, Young K, Halliwell N, Callister JB, Toulson G, Richardson A, Gerhard A, Snowden J, Mann D, Neary D, Nalls MA, Peuralinna T, Jansson L, Isoviita VM, Kaivorinne AL, Hölttä-Vuori M, Ikonen E, Sulkava R, Benatar M, Wuu J, Chiò A, Restagno G, Borghero G, Sabatelli M, ITALSGEN Consortium, Heckerman D, Rogaeva E, Zinman L, Rothstein JD, Sendtner M, Drepper C, Eichler EE, Alkan C, Abdullaev Z, Pack SD, Dutra A, Pak E, Hardy J, Singleton A, Williams NM, Heutink P, Pickering-Brown S, Morris HR, Tienari PJ, Traynor BJ (2011) A hexanucleotide repeat expansion in C9ORF72 is the cause of chromosome 9p21-linked ALS-FTD. Neuron 72, 257-268.

[16] Ghidoni R, Benussi L, Glionna M, Franzoni M, Binetti G (2008) Low plasma progranulin levels predict progranulin mutations in frontotemporal lobar degeneration. Neurology 71, 1235-1239.

[17] Finch N, Baker M, Crook R, Swanson K, Kuntz K, Surtees R, Bisceglio G, Rovelet-Lecrux A, Boeve B, Petersen RC, Dickson DW, Younkin SG, Deramecourt V, Crook J, GraffRadford NR, Rademakers R (2009) Plasma progranulin levels predict progranulin mutation status in frontotemporal dementia patients and asymptomatic family members. Brain 132, 583-591.

[18] Sleegers K, Brouwers N, Van Damme P, Engelborghs S, Gijselinck I, van der Zee J, Peeters K, Mattheijssens M, Cruts M, Vandenberghe R, De Deyn PP, Robberecht W, Van Broeckhoven C (2009) Serum biomarker for progranulinassociated frontotemporal lobar degeneration. Ann Neurol 65, 603-609.

[19] Ghidoni R, Stoppani E, Rossi G, Piccoli E, Albertini V, Paterlini A, Glionna M, Pegoiani E, Agnati LF, Fenoglio C, Scarpini E, Galimberti D, Morbin M, Tagliavini F, Binetti G, Benussi L (2012) Optimal plasma progranulin cutoff value for predicting null progranulin mutations in neurodegenerative diseases: A multicenter Italian study. Neurodegener Dis 9, 121-127.

[20] Binetti G, Benussi L, Roberts S, Villa A, Pasqualetti P, Sheu CF, Gigola L, Lussignoli G, Dal Forno G, Barbiero L, Corbellini G, Green RC, Rossini PM, Ghidoni R (2006) Areas of intervention for genetic counselling of dementia: Cross-cultural comparison between Italians and Americans. Patient Educ Couns 64, 285-293.

[21] Goldman JS, Hahn SE, Catania JW, LaRusse-Eckert S, Butson MB, Rumbaugh M, Strecker MN, Roberts JS, Burke W, Mayeux R, Bird T, American College of Medical Genetics, the National Society of Genetic, Counselors (2011) Genetic counseling and testing for Alzheimer disease: Joint practice guidelines of the American College of Medical Genetics and the National Society of Genetic Counselors. Genet Med 13, 597-605.

[22] Goldman JS (2012) New approaches to genetic counseling and testing for Alzheimer's disease and frontotemporal degeneration. Curr Neurol Neurosci Rep 12, 502-510.

[23] Bruni AC, Conidi ME, Bernardi L (2014) Genetics in degenerative dementia: Current status and applicability. Alzheimer Dis Assoc Disord 28, 199-205.

[24] Gooding HC, Linnenbringer EL, Burack J, Roberts JS, Green RC, Biesecker BB (2006) Genetic susceptibility testing for Alzheimer disease: Motivation to obtain information and control as precursors to coping with increased risk. Patient Educ Couns 64, 259-267.

[25] Evers-Kiebooms G, Decruyenaere M (1998) Predictive testing for Huntington's disease: A challenge for persons at risk and for professionals. Patient Educ Couns 35, 15-26.

[26] Tibben A, Stevens M, de Wert GM, Niermeijer MF, van Duijn CM, van Swieten JC (1997) Preparing for presymptomatic DNA testing for early onset Alzheimer's disease/cerebral haemorrhage and hereditary Pick disease. J Med Genet 34, 63-72.

[27] Macleod R, Tibben A, Frontali M, Evers-Kiebooms G, Jones A, Martinez-Descales A, Roos RA, Editorial Committee and Working Group 'Genetic Testing Counselling' of the European Huntington Disease Network' (2012) Recommendations for the predictive genetic test in Huntington's disease. Clin Genet 83, 221-231.

[28] Robertson M, Brown E, Whalley L (2014) Dementia prevention: Shared questions for research and clinical management. Maturitas 77, 124-127.

[29] The Huntington's Disease Society of America (1994) Guidelines for genetic testing. The Huntington's Disease Society of America, New York.

[30] International Huntington Association (IHA) and the World Federation of Neurology (WFN) Research Group on Huntington's Chorea (1994) Guidelines for the molecular genetics predictive test in Huntington's disease. Neurology 44, 1533-1536.

[31] Murphy M, Black N, Lamping D, McKee C, Sanderson C, Askham J, Marteau T (1998) Consensus development methods, and their use in clinical guideline development. Health Technol Assess 2, 1-88.

[32] McKhann GM, Knopman DS, Chertkow H, Hyman BT, Jack CR Jr., Kawas CH, Klunk WE, Koroshetz WJ, Manly JJ, Mayeux R, Mohs RC, Morris JC, Rossor MN, Scheltens P, Carrillo MC, Thies B, Weintraub S, Phelps $\mathrm{CH}$ (2011) The diagnosis of dementia due to Alzheimer's disease: Recommendations from the National Institute on Aging-Alzheimer's Association workgroups on diagnostic guidelines for Alzheimer's disease. Alzheimers Dement 7, 263-269.

[33] Folstein MF, Folstein SE, McHugh PR (1975) “Mini-mental state". A practical method for grading the cognitive state of patients for the clinician. J Psychiatr Res 12, 189-198.

[34] Morris JC (1993) The Clinical Dementia Rating (CDR): Current version and scoring rules. Neurology 43, 24122414.

[35] Apolone G, Mosconi P, Quattrociocchi L, Gianicolo EAL, Groth N, Ware JE Jr. (2005) Questionario sullo stato di salute SF-12 (Versione Italiana). Istituto di Ricerche Farmacologiche Mario Negri, Milano.

[36] Centro Collaborativo Italiano partecipante al Progetto WHOQOL (1997) Manuale per l'uso degli strumenti 
WHOQOL (Versione Italiana). Dipartimento di Salute Mentale, Organizzazione Mondiale della Sanitá, Ginevra.

[37] Spielberger CD (1989) State-Trait Anxiety Inventory: Bibliography (2nd ed.). Consulting Psychologists Press, Palo Alto, CA.

[38] Beck AT, Ward CH, Mendelson M, Mock J, Erbaugh J (1961) An inventory for measuring depression. Arch Gen Psychiatry 4, 561-571.

[39] Hamilton M (1960) A rating scale for depression. J Neurol Neurosurg Psychiatry 23, 56-62.

[40] Carver CS (1997) You want to measure coping but your protocol's too long: Consider the Brief COPE. Int J Behav Med 4, 92-100.

[41] Friborg O, Barlaug D, Martinussen M, Rosenvinge JH, Hjemdal O (2005) Resilience in relation to personality and intelligence. Int J Methods Psychiatr Res 14, 29-42.

[42] Wallston KA, Wallston BS, DeVellis R (1978) Development of the multidimensional health locus of control (MHLC) scales. Health Educ Monogr 6, 160-170.

[43] Gala C, Musicco F, Durbano F, Cesana B (1995) Italian validation of the multidimensional scale of "Health Locus of Control". New Trends Exp Clin Psychiatry 9, 79-86.

[44] Beck AT, Weissman A, Lester D, Trexler L (1974) The measurement of pessimism: The hopelessness scale. J Consult Clin Psychol 42, 861-865.

[45] Pompili M, Iliceto P, Lester D, Innamorati M, Girardi P, Tatarelli R (2009) BHS Beck Hopelessness Scale: Manuale. Giunti O.S. Organizzazioni Speciali, Firenze, Italy.

[46] Caprara GV, Barbaranelli C, Borgogni L (1993) Big Five Questionnaire. O.S, Organizzazioni Speciali, Firenze.

[47] Caprara GV, Barbaranelli C, Borgogni L (2000) BFQ: Big Five Questionnaire. Manuale (2nded.). O.S, Organizzazioni Speciali, Firenze.

[48] Porteri C, Petrini C (2015) Research involving subjects with Alzheimer's disease in Italy: The possible role of family members. BMC Med Ethics 16, 12.

[49] Loy CT, Schofield PR, Turner AM, Kwok JB (2014) Genetics of dementia. Lancet 383, 828-840.

[50] Wood EM, Falcone D, Suh E, Irwin DJ, Chen-Plotkin AS, Lee EB, Xie SX, Van Deerlin VM, Grossman M (2013) Development and validation of pedigree classification criteria for frontotemporal lobar degeneration. JAMA Neurol 70, 1411-1417.

[51] Duits FH, Teunissen CE, Bouwman FH, Visser PJ, Mattsson N, Zetterberg H, Blennow K, Hansson O, Minthon L, Andreasen N, Marcusson J, Wallin A, Rikkert MO, Tsolaki M, Parnetti L, Herukka SK, Hampel H, De Leon MJ, Schröder J, Aarsland D, Blankenstein MA, Scheltens P, van der Flier WM (2014) The cerebrospinal fluid "Alzheimer profile": Easily said, but what does it mean? Alzheimers Dement 10, 713-723.

[52] Benussi L, Ghidoni R, Pegoiani E, Moretti DV, Zanetti O, Binetti G (2009) Progranulin Leu271LeufsX10 is one of the most common FTLD and CBS associated mutations worldwide. Neurobiol Dis 33, 379-385.

[53] Mitchell JA, Demiris G (2005) Telegenetics: The next phase in the provision of genetics services? Genet Med 7, 1-2.

[54] Zilliacus EM, Meiser B, Lobb EA, Kelly PJ, Barlow-Stewart K, Kirk JA, Spigelman AD, Warwick LJ, Tucker KM (2011) Are videoconferenced consultations as effective as face-toface consultations for hereditary breast and ovarian cancer genetic counseling? Genet Med 13, 933-941.

[55] Goldman JS, Rademakers R, Huey ED, Boxer AL, Mayeux R, Miller BL, Boeve BF (2011) An algorithm for genetic testing of frontotemporal lobar degeneration. Neurology $\mathbf{7 6}$, 475-483.

[56] Borroni B, Padovani A (2013) A new algorithm for molecular diagnostics in FTLD. Nat Rev Neurol 9, 241-242.

[57] Bernardi L, Geracitano S, Colao R, Puccio G, Gallo M, Anfossi M, Frangipane F, Curcio SA, Mirabelli M, Tomaino C, Vasso F, Smirne N, Maletta R, Bruni AC (2009) AbetaPP A713T mutation in late onset Alzheimer's disease with cerebrovascular lesions. J Alzheimers Dis 17, 383-389.

[58] Conidi ME, Bernardi L, Puccio G, Smirne N, Muraca MG, Curcio SA, Colao R, Piscopo P, Gallo M, Anfossi M, Frangipane F, Clodomiro A, Mirabelli M, Vasso F, Cupidi C, Torchia G, Di Lorenzo R, Mandich P, Confaloni A, Maletta RG, Bruni AC (2015) Homozygous carriers of APP A713T mutation in an autosomal dominant Alzheimer disease family. Neurology 84, 2266-2273.

[59] Signorini S, Ghidoni R, Barbiero L, Benussi L, Binetti G (2004) Prevalence of pathogenic mutations in an Italian clinical series of patients with familial dementia. Curr Alzheimer Res 1, 215-218.

[60] Benussi L, Ghidoni R, Binetti G (2010) Progranulin mutations are a common cause of FTLD in Northern Italy. Alzheimer Dis Assoc Disord 24, 308-309.

[61] van der Zee J, Gijselinck I, Dillen L, Van Langenhove T, Theuns J, Engelborghs S, Philtjens S, Vandenbulcke M, Sleegers K, Sieben A, Bäumer V, Maes G, Corsmit E, Borroni B, Padovani A, Archetti S, Perneczky R, Diehl-Schmid J, de Mendonça A, Miltenberger-Miltenyi G, Pereira S, Pimentel J, Nacmias B, Bagnoli S, Sorbi S, Graff C, Chiang HH, Westerlund M, Sanchez-Valle R, Llado A, Gelpi E, Santana I, Almeida MR, Santiago B, Frisoni G, Zanetti O, Bonvicini C, Synofzik M, Maetzler W, Vom Hagen JM, Schöls L, Heneka MT, Jessen F, Matej R, Parobkova E, Kovacs GG, Ströbel T, Sarafov S, Tournev I, Jordanova A, Danek A, Arzberger T, Fabrizi GM, Testi S, Salmon E, Santens P, Martin JJ, Cras P, Vandenberghe R, De Deyn PP, Cruts M, Van Broeckhoven C, European Early-Onset Dementia, Consortium (2013) A pan-European study of the C9orf72 repeat associated with FTLD: Geographic prevalence, genomic instability, and intermediate repeats. Hum Mutat 34, 363-373.

[62] Benussi L, Rossi G, Glionna M, Tonoli E, Piccoli E, Fostinelli S, Paterlini A, Flocco R, Albani D, Pantieri R, Cereda C, Forloni G, Tagliavini F, Binetti G, Ghidoni R (2014) C9ORF72 hexanucleotide repeat number in frontotemporal lobar degeneration: A genotype-phenotype correlation study. J Alzheimers Dis 38, 799-808.

[63] Galimberti D, Fenoglio C, Serpente M, Villa C, Bonsi R, Arighi A, Fumagalli GG, Del Bo R, Bruni AC, Anfossi M, Clodomiro A, Cupidi C, Nacmias B, Sorbi S, Piaceri I, Bagnoli S, Bessi V, Marcone A, Cerami C, Cappa SF, Filippi M, Agosta F, Magnani G, Comi G, Franceschi M, Rainero I, Giordana MT, Rubino E, Ferrero P, Rogaeva E, Xi Z, Confaloni A, Piscopo P, Bruno G, Talarico G, Cagnin A, Clerici F, Dell'Osso B, Comi GP, Altamura AC, Mariani C, Scarpini E (2013) Autosomal dominant frontotemporal lobar degeneration due to the C9ORF72 hexanucleotide repeat expansion: Late-onset psychotic clinical presentation. Biol Psychiatry 74, 384-391.

[64] Bagnoli S, Piaceri I, Tedde A, Piacentini S, Nannucci S, Bracco L, Sorbi S, Nacmias B (2012) Progranulin genetic screening in frontotemporal lobar degeneration patients from central Italy. Cell Mol Neurobiol 32, 13-16.

[65] Bernardi L, Frangipane F, Smirne N, Colao R, Puccio G, Curcio SA, Mirabelli M, Maletta R, Anfossi M, Gallo M, 
Geracitano S, Conidi ME, Di Lorenzo R, Clodomiro A, Cupidi C, Marzano S, Comito F, Valenti V, Zirilli MA, Ghani M, Xi Z, Sato C, Moreno D, Borelli A, Leone RA, St GeorgeHyslop P, Rogaeva E, Bruni AC (2012) Epidemiology and genetics of frontotemporal dementia: A door-to-door survey in southern Italy. Neurobiol Aging 33, 2948.e1-2948.e10.

[66] Beck J, Pittman A, Adamson G, Campbell T, Kenny J, Houlden H, Rohrer JD, de Silva R, Shoai M, Uphill J, Poulter M, Hardy J, Mummery CJ, Warren JD, Schott JM, Fox NC, Rossor MN, Collinge J, Mead S (2014) Validation of nextgeneration sequencing technologies in genetic diagnosis of dementia. Neurobiol Aging 35, 261-265.

[67] Goldberg D (1978) Manual of the General Health Questionnaire. NFER Publishing Co., Great Britain.

[68] Miller SM (1987) Monitoring and blunting: Validation of a questionnaire to assess styles of information seeking under threat. J Pers Soc Psychol 52, 345-353.

[69] Corney RH, Clare AW (1985) The construction, development and testing of a self-report questionnaire to identify social problems. Psychol Med 15, 637-649.

[70] Brugha T, Bebbington P, Tennant C, Hurry J (1985) The List of Threatening Experiences: A subset of 12 life event categories with considerable long-term contextual threat. Psychol Med 15, 189-194.

[71] The WHOQOL Group (1994) The development of the World Health Organization quality of life assessment instrument (the WHOQOL). In Quality of Life Assessment:
International Perspectives, Orley J, Kuyken W, eds. Springer Verlag, Heidelberg, pp. 41-57.

[72] Roberts JS (2000) Anticipating response to predictive genetic testing for Alzheimer's disease. Gerontologist 40, 43-52.

[73] Roberts JS, Connell CM (2000) Illness representations among first-degree relatives of persons with Alzheimer disease. Alzheimer Dis Assoc Disord 14, 129-136.

[74] Hathaway SR, McKinley JC (1997) MMPI-2 - Minnesota Multiphasic Personality Inventory-2, Organizzazioni Speciali, Firenze

[75] Spielberger CD, Gorsuch RL, Lushene RE (1970) Manual for the State-Trait Anxiety Inventory (Self-evaluation questionnaire). Consulting Psychologists Press, Palo Alto, CA.

[76] Zung WW (1965) A self-rating depression scale. Arch Gen Psychiatry 12, 63-70.

[77] Zung WW (1971) A rating instrument for anxiety disorders. Psychosomatics 12, 371-379.

[78] Hathaway SR, McKinley JC (1943) Manual for the Minnesota Multiphasic Personality Inventory, Psychological Corporation, New York.

[79] Carlesimo GA, Caltagirone C, Gainotti G, Fadda L, Gallassi R, Lorusso S, Marfia G, Marra C, Nocentini U, Parnetti L (1996) The Mental Deterioration Battery: Normative data, diagnostic reliability and qualitative analyses of cognitive impairment. Eur Neurol 36, 378-384. 